\title{
ROLE OF PHYSICAL ACTIVITY ON THE MAINTENANCE OF COGNITION AND ACTIVITIES OF DAILY LIVING IN ELDERLY WITH ALZHEIMER'S DISEASE
}

\author{
Cynthia Arcoverde , Andréa Deslandes ${ }^{1,3}$, Aryce Rangel', Andreza Rangel', \\ Robson Pavão ${ }^{2}$, Fortunée Nigri², Eliasz Engelhardt ${ }^{1,2}$, Jerson Laks ${ }^{1,2}$
}

\begin{abstract}
Background: The practice of physical activities has proved to be an efficient strategy in the improvement of independency and cognitive functions in the elderly with Alzheimer's disease (AD). Objective: To evaluate the relation between the practice of physical activity, cognition and activities of daily living (ADL) of patients with AD. Method: The cognitive and physical aspects and ADL were evaluated of 37 elders (19 normal controls, 11 sedentary with $A D$ and 7 active with $A D$ ). Results: The variable that best predicts the cognitive state (MMSE) is the duration of disease for the AD sedentary group and Lawton's Scale for the AD active group. We observed a correlation between MMSE score and duration of disease in the sedentary group and between MMSE and ADL in the active group. Conclusion: Our study showed that physical and cognitive stimulation in patients with $A D$ can contribute to decrease cognitive and functional decline.
\end{abstract}

KEY WORDS: Alzheimer's disease, cognition, ADL, physical exercise, mobility.

\begin{abstract}
Papel da atividade física na manutenção da cognição e atividades de vida diária em idosos com doença de Alzheimer

Resumo - Fundamento: A prática de atividade física tem se mostrado uma estratégia eficaz na melhora da independência e das funções cognitivas em idosos com doença de Alzheimer (DA). Objetivo: Avaliar a relação entre a prática de atividade física, a cognição e as atividades de vida diária (AVD) em pacientes com DA. Método: Foram avaliados os aspectos cognitivos, físicos e as AVD de 37 idosos (19 controles normais, 11 com DA sedentários e 7 com DA ativos). Resultados: A variável que melhor prediz o estado cognitivo (MEEM) foi o tempo de doença para o grupo DA sedentários e a Escala de Lawton para o grupo DA ativo. Observou-se correlação entre MEEM e tempo de doença no grupo sedentário e MEEM e AVD no grupo ativo. Conclusão: $O$ nosso estudo mostrou que a estimulação física e cognitiva em pacientes com DA pode contribuir na diminuição do declínio cognitivo e funcional.
\end{abstract}

PALAVRAS-CHAVE: doença de Alzheimer, AVD, cognição, exercício físico, mobilidade.

The practice of physical activity is associated to a lower prevalence and incidence of dementia and cognitive decline $^{1-3}$. A recent study ${ }^{1}$ found that healthy elderly who exercised regularly were $32 \%$ less prone to developing dementia than a control group of sedentary subjects. Low levels of functional capacity are associated with the risk of dementia whereas a three-day weekly exercise regimen seems to contribute to a protective effect. Convincing evidence has also been presented regarding the improvement of the cognitive functioning with aerobic training independently of the type, duration, and intensity of the physical activity, mainly on the executive processes ${ }^{4}$. Ac- tivities of daily living (ADL) and cognition in Alzheimer's disease $(A D)$ decline according to a temporal and parallel hierarchy ${ }^{5}$. Furthermore, the impairments on the ADL may be related to motor changes and neurological manifestations which occur along the progression of $A D$, such as extrapyramidal signs, myoclonus, and frontal gait ${ }^{6,7}$. These manifestations determine an increased risk of falls, more caregiver burden and stress, increased rates of institutionalization, and death.

Several studies show that the regular practice of physical exercise is an important factor for maintaining balance, physical strength, and cognition in $A D$ patients ${ }^{1,8-10}$.

\footnotetext{
'Laboratório de Neuropsiquiatria Geriátrica, Institute of Phychiatry (IPUB) Universidade Federal do Rio de Janeiro, Rio de Janeiro RJ, Brazil (UFRJ); ${ }^{2}$ Center for Alzheimer's disease and Related Disorders (CDA), IPUB/UFRJ; ${ }^{3}$ Brain Mapping and Sensorimotor Integration Lab, IPUB/UFRJ.
}

Received 17 December 2007, received in final form 24 March 2008. Accepted 2 April 2008.

Dr. Jerson Laks - Avenida Copacabana 749/802 -22050-000 Rio de Janeiro RJ - Brasil.E-mail: jlaks@certroin.com.br 
The expected increased independence in basic and instrumental activities of daily life in subjects with dementia who exercise may lead to a better quality of life and to less economic costs and caregiver burden". Some mechanisms that may contribute to this effect include the improvement of the cerebral blood flow and the induction of neurogenesis in the hippocampus ${ }^{3}$. Few studies have focused on the relationship among exercise, independence in $A D L$, and cognition in elderly with $A D$ in Brazil.

The aim of the present study is to assess the association between the practice of physical activities and the maintenance of cognition and $A D L$ in $A D$ patients who attend a day center, where there are opportunities for cognitive stimulation and exercising.

\section{METHOD}

This is a cross sectional study involving 37 elderly with more than 65 years of age (19 normal controls, 11 sedentary with AD, and 7 active with $A D)$. AD diagnosis was established according to NINCDS-ADRDA criteria ${ }^{12}$, and patients with mild to moderate dementia, with the Mini-Mental State Exam ${ }^{13}$ (MMSE) score ranging from 10 to 26 were included. Subjects with depression, dementia other than $A D$, with any physical limitation consequent to any other clinical disorders, with other neurological disorders, with uncontrolled high blood pressure or diabetes mellitus, or with visual or hearing impairment were excluded from the study.

The study was carried out in two sites. The patients from an outpatient unit where there is also a day center constituted the groups with $A D$ (Center for Alzheimer's disease and Related Disorders/Institute of Psychiatry-CDA of the Federal University of Rio de Janeiro (UFRJ), whereas healthy elderly subjects were recruited at a program for physical education designed to maintenance of independence in ADL (Elderly in Movement Project - Maintaining Autonomy - IMMA Project) and the Third Age Open University - UnATI).

The study protocol was approved by the Ethics Committee of the Institute of Psychiatry/UFRJ and all subjects and legal representatives signed an informed consent form previous to the start of any procedure.

\section{Subjects}

The elderly were classified into three groups, as follows:

Control group - This group consisted of 19 healthy elderly who took part in the IMMA Project and carried out a one-hour group session of physical exercises twice a week for at least six months. The exercises were mainly sessions of recreational activities, dance and gym lessons focused on improving and maintaining balance, flexibility, aerobic capacity, strength and coordination.

Sedentary AD group - AD patients ( $n=11 ; C D R 1=5 ; C D R 2=6$ ) from the outpatient clinic who were not on any regular physical exercise for at least six months.
Active AD group - AD patients ( $n=7 ; C D R 1=2 ; C D R 2=5)$ who attended the day center and participated in a one-hour physiotherapy session twice a week for at least six months. These sessions comprise respiratory exercises, static and dynamic balance training, gait circuits with and without obstacles, and stimulation of activities of daily living and of fine motor coordination and balance. There are also sessions of cognitive stimulation which include reminiscence sessions, and exercises to improve attention, verbal fluency, and general recognition.

\section{Cognitive and functional assessment}

The Clinical Dementia Rating ${ }^{14}$ (CDR) was used to stage the $A D$ patients as mild (CDR1) and moderate (CDR2). The CDR stages dementia ranging from 0 (no dementia) to 3 (severe stage) according to the cognitive, behavioral, and ADL impairments. The Cornell Scale for Depression in Dementia ${ }^{15}$ was used to exclude AD patients who scored above 7, considered a cut-off score for depression. The Cornell assesses mood symptoms, physical signs, circadian functions, and behavioral symptoms related to depression. Scores above 7 are related to the presence of mild, moderate, or severe depression. The healthy elderly were examined with the Hamilton Depression Rating Scale and a cut-off score of 10 was apllied ${ }^{16}$.

The cognitive functions were assessed with the MMSE. The MMSE is a screening tool that assesses orientation, memory, attention, language and praxis, with the score ranging from zero to 30 , being the worst performance zero.

The POMA-Brasil ${ }^{17}$ derived from the English version ${ }^{18} \mathrm{com}^{-}$ prises a part that assesses the mobility during the execution of daily tasks which can cause instability. The second part of the scale assesses gait. POMA-Brasil has a total score of 57 points and a minimum of 22. The higher the score the better the performance on balance and gait.

The "Timed UP and GO Test" (TUGT) 19 measures the basic functional mobility. The patient is asked to get up from a $45 \mathrm{~cm}$ height chair with an arm of $65 \mathrm{~cm}$, to walk 3 meters, turn back and sit down again. Independent subjects without balance problems perform this task in up to $10 \mathrm{sec}$, whereas patients who take more than $30 \mathrm{sec}$ to perform the test are considered to be dependent in ADL and mobility, with increased risk of falls.

The basic and instrumental ADL were assessed using the scales designed by Lawton and Brody ${ }^{20}$ which measure independence and autonomy in seven domains, namely personal care, domestic affairs, job and recreation, dealing with money and shopping, locomotion, communication and social relations. This test has a total score of 90 points, the higher the score the worse the autonomy and the independence. A score above 45 indicates a major impairment.

\section{Statistical analysis}

We used the Kruskal Wallis test to compare the dependent variables among the three groups (controls, sedentary AD, and 
Table 1. Sociodemographic and cognitive and functional description of the sedentary and active AD groups and of the control group.

\begin{tabular}{|c|c|c|c|c|c|}
\hline & Group & Mean & SD & $\mathrm{F}$ & $P$ value \\
\hline \multirow[t]{3}{*}{ Age (years) } & control & 76.3 & 6.1 & 4.754 & $0.015^{*}$ \\
\hline & physical activity & 81.2 & 4.5 & & \\
\hline & sedentary & 72.5 & 6.0 & & \\
\hline \multirow[t]{3}{*}{ Education (years) } & control & 11.6 & 4.2 & 1.78 & 0.183 \\
\hline & physical activity & 11.5 & 3.2 & & \\
\hline & sedentary & 9.0 & 2.8 & & \\
\hline \multirow[t]{3}{*}{ MMSE (score) } & control & 26.4 & 2.5 & 38.4 & $0.000 *$ \\
\hline & physical activity & 15.4 & 5.4 & & \\
\hline & sedentary & 15.9 & 4.2 & & \\
\hline \multirow[t]{3}{*}{ LAWTON scale } & control & 0.8 & 1.4 & 94.3 & $0.000 *$ \\
\hline & physical activity & 48.2 & 12.3 & & \\
\hline & sedentary & 46 & 16.0 & & \\
\hline \multirow[t]{3}{*}{ POMA-BR } & control & 54.2 & 2.0 & 6.16 & $0.005^{*}$ \\
\hline & physical activity & 47.2 & 7.8 & & \\
\hline & sedentary & 49.1 & 6.6 & & \\
\hline \multirow[t]{3}{*}{ TUGT (ms) } & control & 785.6 & 174.8 & 10.1 & $0.000 *$ \\
\hline & physical activity & 1269.0 & 344.8 & & \\
\hline & sedentary & 1318.2 & 534.2 & & \\
\hline \multirow[t]{3}{*}{ Duration of disease (years) } & control & 0 & 0 & 1.0 & 0.332 \\
\hline & physical activity & 6.4 & 2.8 & & \\
\hline & sedentary & 5 & 3 & & \\
\hline
\end{tabular}

*Significant difference $(p<0.05)$.

Table 2. Correlation between MMSE and sociodemographic and functional variables of sedentary and active $A D$ patients.

\begin{tabular}{lccccc}
\hline Variable & \multicolumn{2}{c}{ Physical activity $(\mathrm{n}=7)$} & & \multicolumn{2}{c}{ Sedentary $(\mathrm{n}=11)$} \\
\cline { 2 - 3 } \cline { 5 - 6 } \cline { 5 - 6 } Age & $\mathrm{r}$ Spearman & $\mathrm{p}$ value & & $\mathrm{r}$ Spearman & $\mathrm{p}$ value \\
\hline Education & -0.464 & 0.295 & & 0.355 & 0.284 \\
Duration of disease & -0.614 & 0.143 & & 0.116 & 0.735 \\
LAWTON & -0.241 & 0.603 & & -0.604 & $0.049^{*}$ \\
POMA-BR & -0.945 & $0.001^{*}$ & & -0.275 & 0.414 \\
TUGT & 0.964 & $0.000^{*}$ & & 0.402 & 0.22 \\
\hline
\end{tabular}

*Significant difference $(p<0.05)$.

active $A D)$. A stepwise multiple regression analysis was used to determine the variable which could better predict the cognitive state in the groups whereas the Spearman correlation test was used to assess the associations among the variables ( $p>0.05)$.

\section{RESULTS}

As expected, the AD groups showed significant lower scores on the cognitive state (MMSE) and on the data regarding balance and gait (POMA-BR), and higher scores regarding mobility (TUGT) and ADL (Lawton), in comparison to the healthy groups. Specifically in AD patients, there was a significant age difference between the two groups (active and sedentary AD). However, there were no significant differences regarding balance and gait (POMA-BR), and ADL (Lawton). There was a tendency for better results in mobility (TUGT) in the active AD patients. Table 1 depicts the socio-demographic and clinical characteristics of the sample.

Table 2 presents the correlations between cognition, the socio-demographic, and the functional variables of sedentary and active AD patients.

While the MMSE showed no significant correlation with age and education between the AD groups, there was a negative correlation with duration of disease in the 


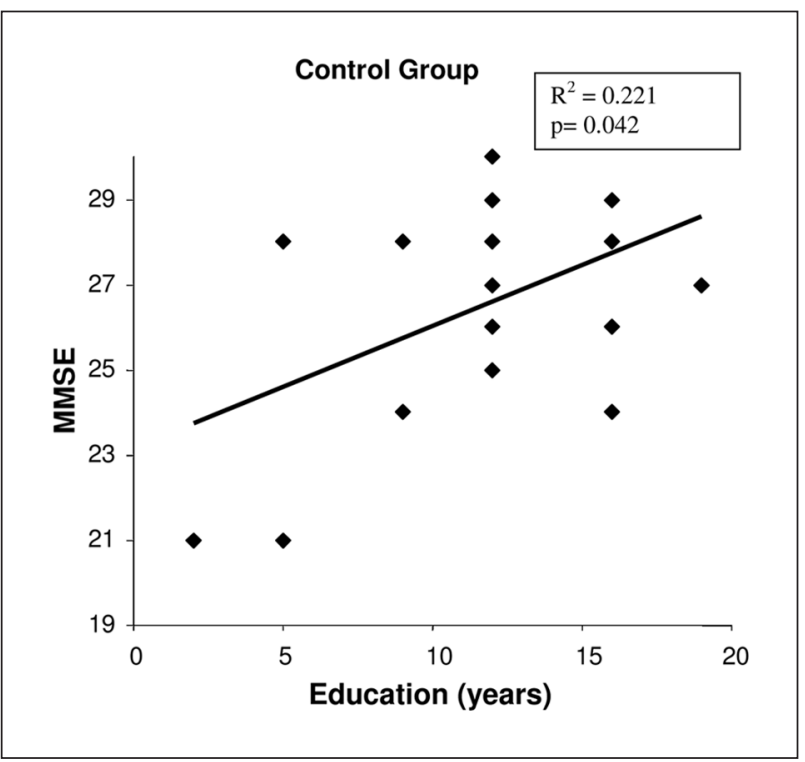

Fig 1. Stepwise regression shows education as the better predictor for MMSE in the control group.

sedentary AD group but not in the active AD group. The MMSE correlated favorably with balance and ADL in the active AD group.

The forward multiple regression analysis showed different result in the three groups. The variable that best correlated with cognition (MMSE) in the control group was education $\left(R^{2}=0.221 ; p=0.042\right)$. In the sedentary $A D$ group, duration of disease showed a negative impact regarding cognition $\left(R^{2}=0.372 ; p=0.042\right)$. The active $A D$ group had a better cognitive scores correlated with better performance in $A D L\left(R^{2}=0.92 ; p=0.001\right)$. Figures 1,2 , and 3 present the correlations between the predictive variables in each group.

\section{DISCUSSION}

This study presents data on the practice of physical exercise performed in a day center setting that positively influenced on the cognitive and functional capacity of $A D$ patients as compared to sedentary AD patients. Noteworthy, the $A D$ patients who attended the day center and the exercise sessions were approximately 10 years older than the patients in the sedentary AD group, with no differences on all other socio-demographic variables. Nevertheless, there was no significant difference on cognition, balance, and activities of daily living between both groups. Being older might have a negative influence on cognition, balance and independence in activities of daily living, as usually reported ${ }^{21,22}$. The aging process is associated with a $15 \%$ decline in strength during the sixth and seventh decade, with a $30 \%$ decline each decade ${ }^{22,23}$. This is one of the contributing factors for limited capacity of coordination and static and dynamic balance control ${ }^{21}$. Some

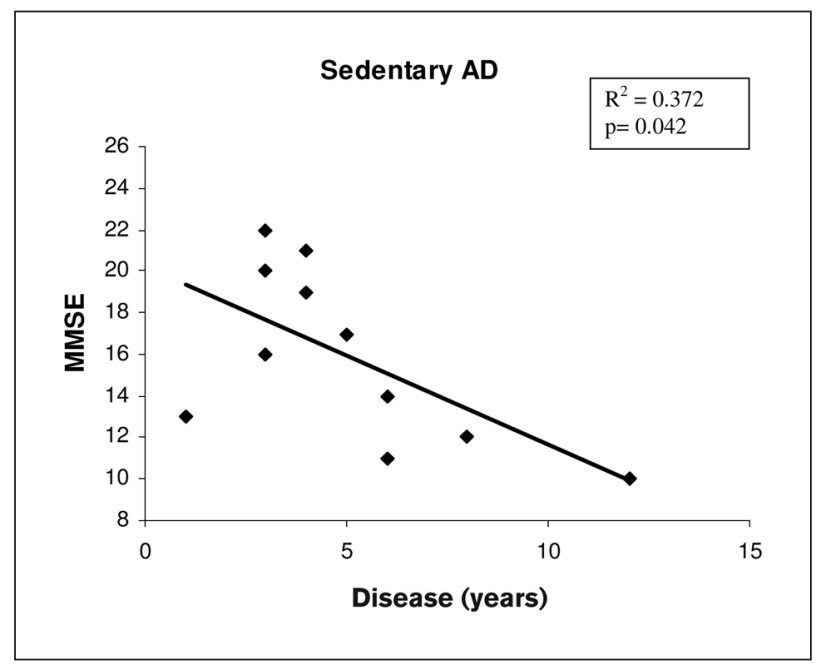

Fig 2. Stepwise regression shows duration of disease as the better predictor for MMSE in the sedentary AD group.

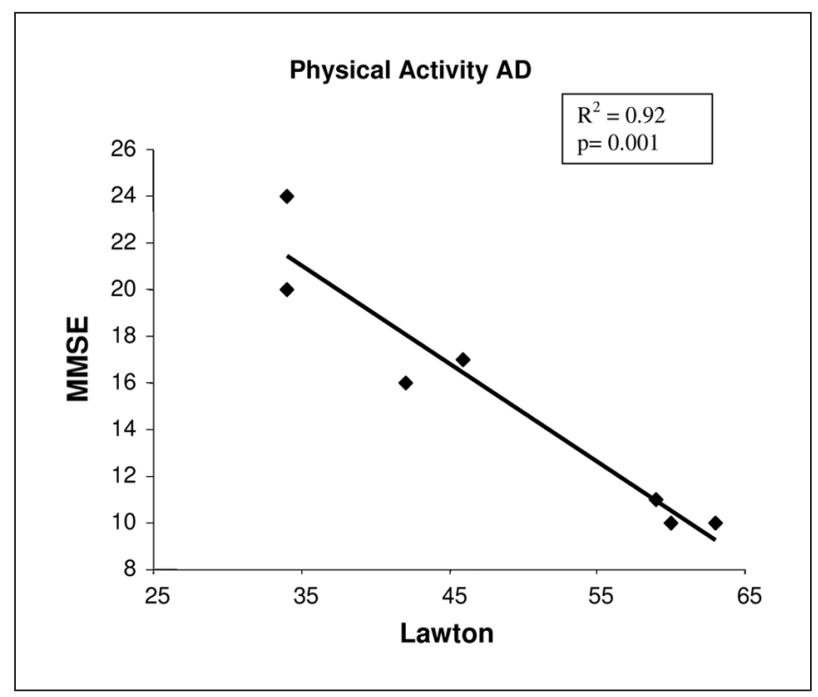

Fig 3. Stepwise regression shows activities of daily living as the better predictor for MMSE in the AD patients who exercise.

other studies also show a decrease in gait speed associated with a shortened extension and dyscoordination of the step which occur in dementia ${ }^{24,25}$. The sedentary and the active $A D$ groups showed the same mobility scores as assessed by the TUGT. This is in line with another study ${ }^{26}$ which found the same results using this instrument in institutionalized elderly.

The need of assistance in activities of daily living is associated with age ${ }^{27}$ and with the cognitive status ${ }^{22}$ in patients with dementia. However, our study found that the active $A D$ group presented with the same degree of dependence as found in sedentary AD patients notwithstanding the fact that the latter group was significantly younger than the former group. A conceivable reason for this finding could be the practicing of physical exercise, 
given that Rolland et al. ${ }^{8}$ observed improvement on activities of daily living in $A D$ after a six month training trial.

As expected, the healthy control group showed better cognitive and functional status than the two other groups and education was the best predictor of overall cognitive functions. On the other hand, AD groups presented differing results concerning cognition. Duration of disease was the best predictor of cognition in the sedentary AD group, an expected result as well ${ }^{5}$. However, this was not the result on the active AD group. The best predictor of cognition in this group was the score on ADL, meaning that the greater the autonomy the better the cognitive function. Once again, it is conceivable to hypothesize that the autonomy provided by keeping an active regimen of exercise might have influenced on the maintenance of cognition.

The adjunctive treatment including drugs, cognitive rehabilitation, and physical exercise is reported to ameliorate the cognitive and functional deficits as well as it may be able to speed down the rate of decline ${ }^{28}$. Furthermore, exercise can prevent and reduce the risk of developing certain secondary conditions which result in functional decline, inactivity, and falls ${ }^{6-8,25}$.

Some limitations of the present study warrant consideration. The small number of patients and the cross sectional design preclude us from affirming a causal relationship between exercise and cognitive and functional status. Longitudinal studies with these groups may show whether the present findings are found. Despite the fact that the training program of the active $A D$ patients was mainly focused on physical exercises, they were also offered some cognitive stimulation. This may have contributed to the better performance observed in this group, since multidisciplinary interventions are able to improve the quality of life of AD patients.

To sum up, this study showed that physical and cognitive stimulation in patients with AD may contribute to a less aggressive progression of the cognitive and functional status as compared to sedentary AD patients.

\section{REFERENCES}

1. Larson EB, Wang L, Bowen JD, et al. Exercise is associated with reduced risk for incident dementia among persons 65 years of age and older. Ann Intern Med 2006;144:73-81.

2. Colcombe SJ, Erickson KI, Raz N, et al. Aerobic fitness reduces brain tissue loss in aging humans. J Gerontol A Biol Sci Med Sci 2003;58:176-180.

3. Gómez P, So V, Kesslak JP. Spatial learning and physical activity contribute to the induction of fibroblast growth factor: neural substrates for increased cognition associated with exercise. Neuroscience 1998;85:53-61.
4. Colcombe S, Kramer AF. Fitness effects on the cognitive function of older adults: a meta-analytic study. Psychol Sci 2003;14: 125-130.

5. Bottino CM, Laks J, Blay SL. Demência e transtornos cognitivos em idosos. In Diagnóstico clínico na doença de Alzheimer. Rio de Janeiro: Guanabara Koogan, 2006:173-176.

6. Engelhardt E, Laks J, Rozenthal M, Marinho V. Doença de Alzheimer: manifestações neurológicas. Rev Bras Neurol 2000;36:43-51.

7. Camicioli R, Bouchard T, Licis L. Dual- Tasks and walking fast: relationship to extra- pyramidal signs in advanced Alzheimer's disease. J Neurol Sci 2006;248:205-209.

8. Rolland Y, Pillard F, Klapouszczak A, et al. Exercise program for nursing home residents with Alzheimer's disease: a 1- year randomized, controlled trial. JAGS 2007;55:158-165.

9. Heyn P, Abreu BC, Ottenbacher KJ. The effects of exercise training on elderly persons with cognitive impairment and dementia: a meta-analysis. Arch Phys Med Rehabil 2004;85:1694- 704.

10. Eggermont L, Swaab D, Luiten P, Scherder E. Exercise, cognition and Alzheimer's disease: more is not necessarily better. Neurosc Biob Rev 2006;30:562-575.

11. Prigerson HG. Costs to society of family caregiving for patients with end-stage Alzheimer's disease. N Engl J Med 2003;349:1891-1892.

12. McKhann G, Drachman D, Folstein M, Katzman R, Price D, Stadlan EM. Clinical diagnosis of Alzheimer's disease: report of the NINCDSADRDA Work Group under the auspices of department of health and human services task force on Alzheimer's disease. Neurology 1984;34:939-944.

13. Folstein MF, Folstein SE, Mchugh PR. Mini-mental state: a practical method for grading the cognitive state of patients for the clinician. J Psychiatric Res 1975;12:189-198

14. Hughes CP, Berg L, Danziger WL, Coben LA, Martin RL. A new clinical scale for the staging of dementia. Br J Psychiatry 1982;140:566-572.

15. Alexopoulos GS, Abrams RC, Young RC, Shamoian CA. Cornell scale for depression in dementia. Biol Psychiatry 1998;23:271-284.

16. Hamilton M. A rating scale for depression. J Neurol Neurosurg Psychiatry 1960;23:56-62.

17. Gomes GC. Tradução, adaptação transcultural e exame das propriedades de medida da escala "Performance Oriented Mobility Assessment" (POMA) para uma amostragem de idosos brasileiros institucionalizados. Dissertação. Campinas, 2003.

18. Tinetti M. Performance- oriented assessment of mobility problems in elderly patients. JAMA 1986;34:119-126.

19. Podsiadlo D, Richardson S. The timed "Up and Go": a test of basic functional mobility for frail elderly persons. JAMA 1991;39:142-148.

20. Lawton MP, Brody EM. Assessment of older people: self maintaining and instrumental activities of daily living. Gerontologist 1969;9:179-186.

21. Duthie EH, Katz PR. Practice of geriatrics. Philadelphia: Saunders Co, 1998.

22. Steen G, Sonn U, Hanson AB, Steen B. Cognitive function and functional ability: a cross- sectional and longitudinal study at ages 85 and 95 in non- demented population. Aging 2001;13:68-77.

23. Harries JM, Bassey EJ. Torque- velocity relationship for the knee stensors en women in their 3th an 7 rd decades. Eur J Appl Physiol 1990;60:87-90.

24. Van Lersel MB, Hoefsloot W, Munneke M, Bloem BR, Rikkert MGMO. Systematic review of quantitative clinical gait analysis in patients with dementia. Z Gerontol Geriat 2004;37:27-32.

25. Kato EM.Correlation between balance and functional capacity in the Alzheimer's disease. Dissertação de Mestrado. São Paulo, 2006.

26. Oliveira DLC, Goretti LC, Pereira LSM. O desempenho de idosos institucionalizados com alterações cognitivas em atividades de vida diária e mobilidade: estudo piloto. Rev Bras Fisiot 2006;10:91-96.

27. Chaimowicz F. Os idosos Brasileiros no século XXI Demografia, saúde e sociedade. Belo Horizonte: Postgraduate, 1998.

28. Bottino CM, Carvalho IAM, Alvarez AMMA, et al. Reabilitação cognitiva em pacientes com doença de Alzheimer: relato de trabalho em equipe multidisciplinar. Arq Neuropsiquiatr 2002;60:70-79. 